\title{
Verifikasi Luas Lapangan Radiasi penyinaran Linac Tipe Clinac CX Terintegrasi Electronic Portal Imaging Device (EPID) Menggunakan Teknik IMRT Di RSP Universitas Andalas
}

\author{
Bagus Sidik Waskito Hadi", Dian Milvita \\ Jurusan Fisika FMIPA, Universitas Andalas, Padang \\ *bagussidikw.h@gmail.com
}

\begin{abstract}
ABSTRAK
Telah dilakukan penelitian untuk memverifikasi luas lapangan radiasi penyinaran pesawat Linac tipe Clinac CX terintegrasi EPID dengan teknik IMRT. Verifikasi ini bertujuan untuk mengetahui kondisi pesawat Linac yang dimiliki oleh RSP Universitas Andalas. Pesawat Linac adalah alat terapi radiasi eksternal yang digunakan untuk mengobati penyakit kanker. Electronic Portal Imaging Device (EPID) adalah perangkat tambahan yang terintegrasikan pada perangkat Linac dan digunakan untuk verifikasi dosis radiasi penyinaran. Intensity Modulated Radiation Therapy (IMRT) merupakan teknik radioterapi yang menggunakan banyak lapangan radiasi dalam penyinarannya. Penelitian menggunakan Multi Cube sebagai pengganti tubuh pasien. Variasi luas lapangan yang digunakan pada penelitian ini adalah lapangan persegi $(5 \times 5) \mathrm{cm}^{2}$ sampai $(29 \times 29) \mathrm{cm}^{2}$ dengan interval $2 \mathrm{~cm}$ dan dengan energi berkas foton $6 \mathrm{MV}$ dan $10 \mathrm{MV}$. Hasil verifikasi luas lapangan radiasi penyinaran menunjukkan hubungan yang linear antara MU penyinaran Linac dan Luas lapangan radiasi untuk energi 6 MV dengan nilai $\mathrm{R}^{2}$ sebesar 0,9362 dan energi $10 \mathrm{MV}$ dengan nilai $\mathrm{R}^{2}$ sebesar 0,9213. Verifikasi luas lapangan menunjukkan semakin besar luas lapangan radiasi, maka semakin besar pula MU penyinaran Linac yang digunakan. Hal ini menunjukkan bahwa Linac tipe Clinac CX milik rumah sakit Universitas Andalas berada dalam kondisi baik dan dapat digunakan untuk mengobati pasien penyakit kanker.
\end{abstract}

Kata kunci: Electronic Portal Imaging Device (EPID), Intensity Modulated Radiation Therapy (IMRT), Linac, Multi Cube.

\begin{abstract}
A research to verify field size radiation using Linac type Clinac CX integrated with EPID with IMRT technique of Andalas University Hospital has been conducted. Linac is an external radiation device used to cancer therapy. Electronic Portal Imaging Device (EPID) is an additional device integrated in Linac and used for verification of dose radiation. Intensity Modulated Radiation Therapy (IMRT) is a modern technique in radiotherapy that uses many radiation fields. Multi Cube used to avoid a living subject to direct risk. This study applied for radiation field size $(5 \times 5) \mathrm{cm}^{2}$ to $(29 \times 29) \mathrm{cm}^{2}$ with $2 \mathrm{~cm}$ intervals for the variations and used $6 \mathrm{MV}$ and $10 \mathrm{MV}$ energy of photon. Verification of radiation dose has been performed by field size depedence measurements. The results of verification field size showed a linear relationship between monitor unit $(M U)$ and field zise radiation for $6 \mathrm{MV}$ energy radiation with $R^{2}$ value of 0.9362 and $10 \mathrm{MV}$ energy radiation with $R^{2}$ value of 0.9213 . Verification field size radiation showed that Linac type Clinac CX owned by Andalas University hospital is in good condition and can be used to treat cancer.

Keywords: Electronic Portal Imaging Device (EPID), Intensity Modulated Radiation Therapy (IMRT), Linac, Multi Cube.
\end{abstract}

\section{PENDAHULUAN}

Kanker adalah penyakit yang sangat ditakuti di dunia, karena kemunculannya dapat merusak sel sehat disekitarnya atau organ penting lainnya. Perlu dilakukan pendeteksian dan dihentikan pertumbuhannya sebelum berdampak lebih buruk terhadap sel sehat. Aplikasi radiasi pada pengobatan penyakit kanker yang berlandasan pada aspek-aspek onkologi saat ini lebih diterima dengan terminologi Radiasi Onkologi (Radiation Oncology). Bersama-sama dengan bedah Onkologi dan pengobatan dengan kemoterapi, radioterapi telah berhasil meningkatkan angka kesembuhan penyakit kanker. Radioterapi atau terapi radiasi adalah pengobatan kanker dengan menggunakan radiasi pengion. Metode yang umum digunakan pada radioterapi adalah teleterapi. Pesawat teleterapi terdiri dari pesawat terapi Cesium-137 (Cs137), pesawat terapi Linear Accelerator (Linac) dan pesawat terapi Cobalt-60 (Co-60). Teknik penyinaran linac yang ada saat ini adalah Three Dimension Recontruction Tehnique (teknik 3DRCT) dan Intensity Modulated Radiation Therapy (teknik IMRT). Teknik penyinaran IMRT dan 3DRCT menggunakan komputer saat melakukan treatment (Susworo, 2007). 
Setiap kasus kanker yang menggunakan pesawat terapi harus dilakukan verifikasi terlebih dahulu, sesuai dengan standar International Atomic Energy Agency (IAEA) No. 31 tahun 2016. Hal ini juga tertuang dalam Peraturan Kepala Badan Pengawas Tenaga Nuklir (BAPETEN) nomor 3 tahun 2013 mengenai keselamatan radiasi. Verifikasi keselamatan radiasi meliputi pengkajian keselamatan sumber, pengukuran parameter keselamatan dan rekaman hasil verifikasi keselamatan. Salah satu bentuk rekaman hasil verifikasi keselamatan adalah verifikasi dosis radiasi dengan melakukan verifikasi luas lapangan radiasi penyinaran.

Verifikasi dosis radiasi dapat dilakukan menggunakan Electronic Portal Imaging Device (EPID). EPID merupakan sebuah perangkat tambahan yang diintegrasikan pada perangkat Linac. Perangkat ini menghasilkan citra dua dimensi dengan sistem elektronik/digital yang dapat langsung dilihat pada monitor komputer. EPID pada awalnya hanya digunakan untuk verifikasi posisi pasien (verifikasi geometri) namun saat ini EPID telah dikembangkan untuk mengidentifikasi kesalahan perhitungan dosis radiasi penyinaran (Mayles, 2007).

Penelitian menggunakan EPID telah dilakukan oleh Grzadiel (2007) kepada 15 pasien kanker nasofaring dengan membandingkan nilai gamma indeks dengan data Treatment Planning System (TPS). TPS merupakan perangkat lunak yang digunakan untuk menggambar dan menghitung distribusi dosis radiasi yang akan diberikan ke pasien. Hasil penelitian Grzadiel menunjukkan bahwa EPID dapat digunakan untuk mengukur dosis radiasi dengan nilai gamma indeks 0,212 sampai 0,484 untuk masing-masing pasien kanker nasofaring, pengukuran respon linearitas dengan hasil yang linear antara sinyal EPID (CU) dan luas lapangan penyinaran. Selanjutnya, hasil verifikasi luas lapangan radiasi yang linier antara nilai Monitor Unit (MU) dengan luas lapangan radiasi. MU adalah satuan yang digunakan untuk menghitung dosis radiasi Linac dari jarak $100 \mathrm{~cm}$ pada luas lapangan $(10 \mathrm{x} 10) \mathrm{cm}^{2}$. Penelitian menggunakan EPID juga dilakukan oleh Peca (2017) dengan mencari rasio korelasi dengan variasi ketebalan slab fantom, luas lapangan radiasi dan MU penyinaran Linac. Hasil dari penelitian Peca adalah rekontruksi dosis hampir seluruhnya berada 3\% dalam dosis radiasi yang telah diplanning sebelumnya. Dosis radiasi berada dalam rentang 1,5\% untuk kasus isosenter yang diubah $1 \mathrm{~cm}$ di atas isosenter awal dan $4 \%$ untuk perubahan $1 \mathrm{~cm}$ di bawah isosenter awal.

\section{METODE}

Pada penelitian ini dilakukan verifikasi luas lapangan radiasi penyinaran Linac yang terintegrasi EPID dengan teknik IMRT. Teknik IMRT digunakan karena dosis radiasi lebih efektif aman dikirim ke tumor dengan efek samping yang lebih sedikit dibandingkan dengan teknik 3DRCT. EPID dipilih karena alat ini dapat melakukan verifikasi luas lapangan radiasi penyinaran secara komputerisasi. EPID juga terintegrasi pada pesawat Linac sehingga lebih efisien digunakan. Pesawat Linac yang digunakan adalah Instrumentasi pesawat Linac tipe Clinac CX milik Rumah Sakit Universitas Andalas Padang. Multi cube digunakan sebagai pengganti tubuh manusia untuk meminimalisir ancaman kepada jaringan sehat dan merupakan anjuran dari IAEA. Penelitian dilakukan menggunakan berkas foton energi $6 \mathrm{MV}$ dan $10 \mathrm{MV}$. Variasi luas yang digunakan pada penelitian terdiri dari lapangan persegi $(5 \times 5) \mathrm{cm}^{2}$ sampai $(29 \times 29) \mathrm{cm}^{2}$ dengan interval $2 \mathrm{~cm}$. Radiasi yang diberikan diambil dari data TPS dengan Dosis 50 cGy dalam 3 fraksi. perancangan TPS untuk menentukan nilai MU terlebih dahulu dilakukan sebelum Verifikasi luas lapangan radiasi penyinaran

\section{HASIL DAN DISKUSI}

\subsection{Perancangan TPS energi $6 \mathrm{MV}$ dan $10 \mathrm{MV}$}

Nilai MU penyinaran Linac setiap luas lapangan radiasi dan nilai MU perancangan TPS energi $6 \mathrm{MV}$ yang diperlihatkan pada Tabel 1 dan energi $10 \mathrm{MV}$ yang diperlihatkan pada Tabel 2 memiliki nilai error sebesar $0 \%$. Hal ini berada dalam rentang nilai kriteria yang ditetapkan didalam IAEA HUMAN HEALT SERIES No. 31 Accuracy Requirements and Uncertainties in Radiotheraphy yaitu $3 \%$. Analisis terhadap data perancang TPS pada energi $6 \mathrm{MV}$ memperlihatkan bahwa algoritma perhitungan komputer pesawat Linac sangat baik dan tidak terjadi error pada sistem server. 
Tabel 1 Data perancangan TPS energi $6 \mathrm{MV}$

\begin{tabular}{ccc}
\hline $\begin{array}{c}\text { Lapangan } \\
\text { penyinaran } \\
\text { Persegi (cm }\end{array}$ & $\begin{array}{c}\text { Monitor Unit (MU) } \\
\text { TPS }\end{array}$ & $\begin{array}{c}\text { Monitor Unit (MU) } \\
\text { penyinaran Linac }\end{array}$ \\
\hline $5 \times 5$ & 95 & 95 \\
7 × 7 & 98 & 98 \\
$9 \times 9$ & 92 & 92 \\
$11 \times 11$ & 102 & 102 \\
$13 \times 13$ & 102 & 102 \\
$15 \times 15$ & 146 & 146 \\
$17 \times 17$ & 161 & 161 \\
$19 \times 19$ & 164 & 164 \\
$21 \times 21$ & 166 & 166 \\
$23 \times 23$ & 176 & 176 \\
$25 \times 25$ & 260 & 260 \\
$27 \times 27$ & 261 & 261 \\
$29 \times 29$ & 267 & 267 \\
\hline
\end{tabular}

Tabel 2 Data perancangan TPS energi $10 \mathrm{MV}$

\begin{tabular}{ccc}
\hline $\begin{array}{c}\text { Lapangan } \\
\text { penyinaran } \\
\text { Persegi }\left(\mathbf{c m}^{2}\right)\end{array}$ & $\begin{array}{c}\text { Monitor Unit (MU) } \\
\text { TPS }\end{array}$ & $\begin{array}{c}\text { Monitor Unit (MU) } \\
\text { penyinaran Linac }\end{array}$ \\
\hline $5 \times 5$ & 88 & 88 \\
$7 \times 7$ & 91 & 91 \\
$9 \times 9$ & 85 & 85 \\
$11 \times 11$ & 94 & 94 \\
$13 \times 13$ & 95 & 95 \\
$15 \times 15$ & 146 & 146 \\
$17 \times 17$ & 148 & 148 \\
$19 \times 19$ & 152 & 152 \\
$21 \times 21$ & 154 & 154 \\
$23 \times 23$ & 238 & 238 \\
$25 \times 25$ & 243 & 243 \\
$27 \times 7$ & 243 & 243 \\
$29 \times 29$ & 250 & 250 \\
\hline
\end{tabular}

Jika dibandingkan dengan hasil penelitian Peca (2017 yang memiliki nilai error 2,5\% untuk 40 data MU penyinaran Linac, maka data perancangan TPS energi 6 MV dan data perancangan TPS energi $10 \mathrm{MV}$ masih berada dalam rentang nilai kriteria yang ditetapkan di dalam IAEA HUMAN HEALT SERIES No. 31 Accuracy Requirements and Uncertainties in Radiotheraphy yaitu $3 \%$. Ketidaksesuaian nilai MU penyinaran Linac dengan MU perancangan TPS dapat mengakibatkan terjadinya penyinaran dosis yang berlebih pada jaringan sehat atau jaringan normal lainnya sehingga menimbulkan efek biologis yang dapat memicu terjadinya penyakit kanker.

\subsection{Verifikasi Luas Lapangan Radiasi penyinaran}

Verifikasi luas lapangan radiasi dilakukan pada pesawat Linac tipe Clinac CX yang diintergrasi dengan EPID. Verifikasi luas lapangan radiasi dilakukan dengan energi $6 \mathrm{MV}$ dan $10 \mathrm{MV}$. Hasil verifikasi luas lapangan radiasi penyinaran dibuat dalam bentuk grafik dengan hubungan sumbu $\mathrm{X}$ mewakili luas lapangan radiasi dan sumbu $\mathrm{Y}$ mewakili variasi Monitor Unit. Hasil verifikasi luas lapangan radiasi energi $6 \mathrm{MV}$ dapat dilihat pada Gambar 1 dan energi 10 MV dapat dilihat pada Gambar 2. 


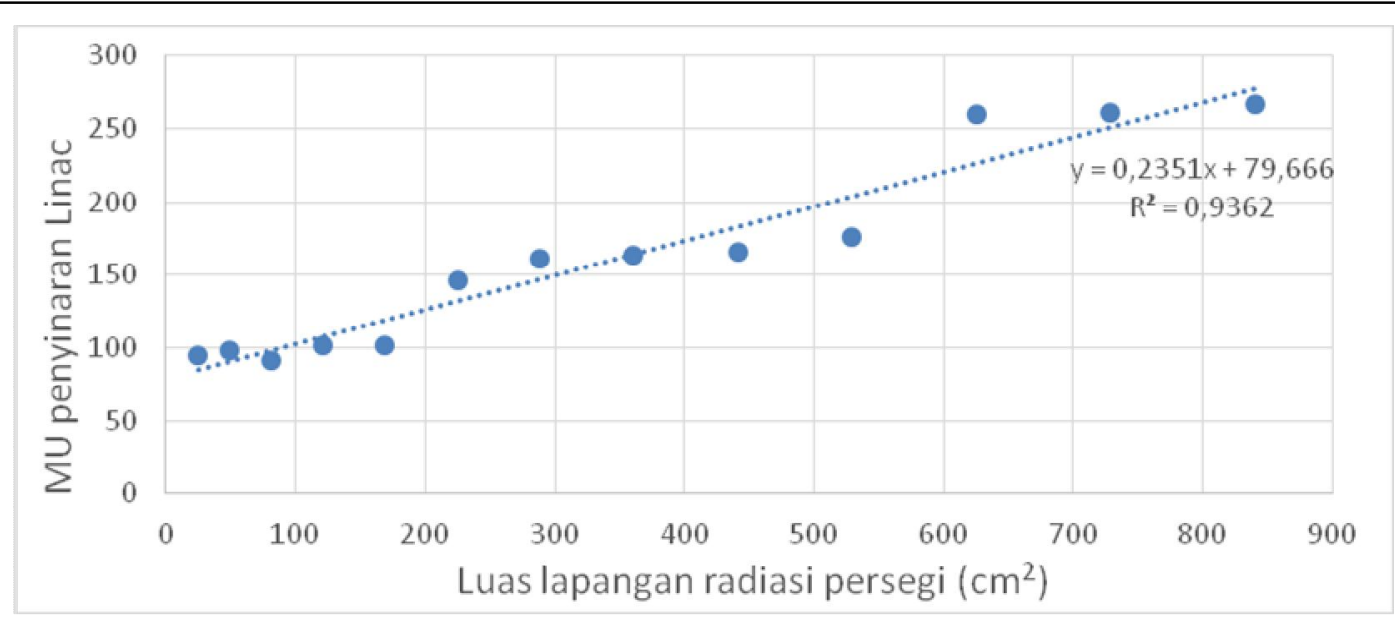

Gambar 1 Verifikasi luas lapangan radiasi berenergi $6 \mathrm{MV}$

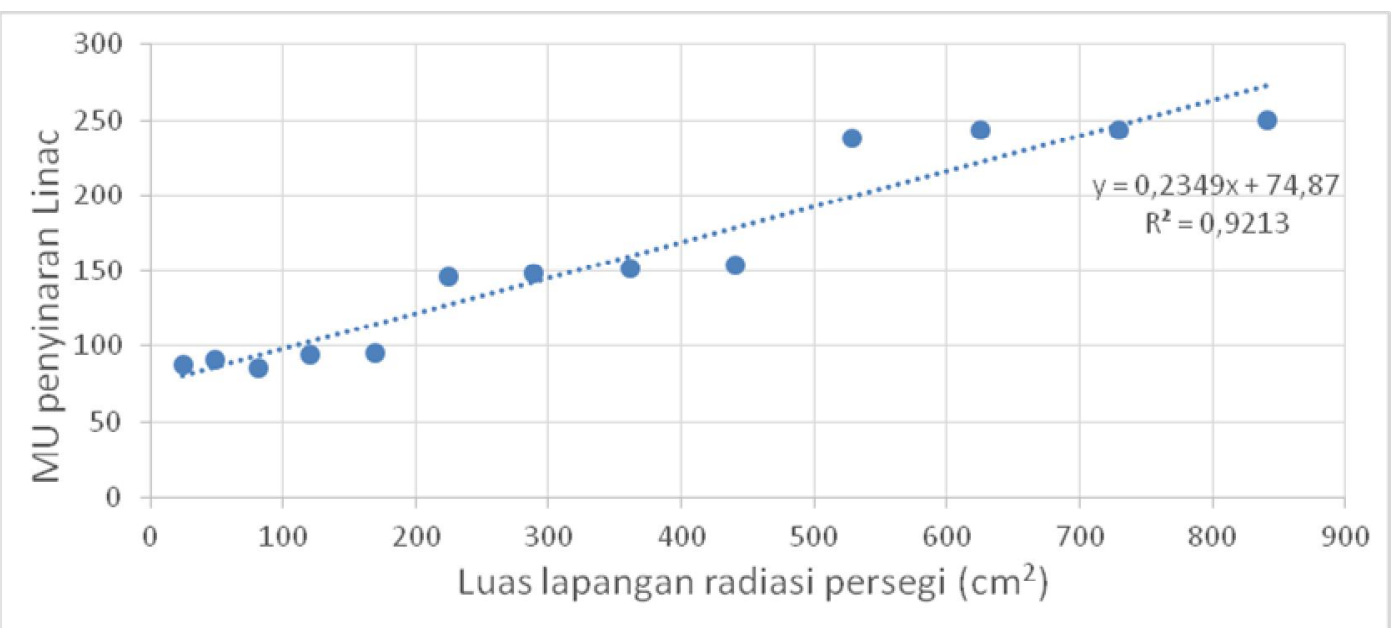

Gambar 2 Verifikasi luas lapangan radiasi energi $10 \mathrm{MV}$

Hasil verifikasi luas lapangan radiasi menunjukkan hubungan yang linear antara MU penyinaran Linac dan luas lapangan radiasi persegi untuk energi $6 \mathrm{MV}$ dengan nilai $\mathrm{R}^{2}$ sebesar 0,9362 dan energi $10 \mathrm{MV}$ dengan nilai $\mathrm{R}^{2}$ sebesar 0,9213 . Hasil verifikasi luas lapangan radiasi memperlihatkan semakin besar luas lapangan radiasi, maka semakin besar pula MU penyinaran Linac yang digunakan. Hal ini berbeda dengan hasil penelitian Grządziel (2007) yang memiliki nilai error $9 \%$ untuk pengukuran nilai MU.

\section{KESIMPULAN}

Perancangan TPS yang dilakukan terhadap variasi luas lapangan radiasi penyinaran dan MU penyinaran Linac di RSP Universitas Andalas menunjukkan hasil yang baik, dimana nilai MU yang dirancang di TPS sama dengan nilai MU yang disinari Linac baik untuk energi 6 MV maupun $10 \mathrm{MV}$. Dari hasil verifikasi luas lapangan radiasi penyinaran Linac energi $6 \mathrm{MV}$ dan 10 MV menunjukkan hubungan yang linear antara MU penyinaran Linac dan luas lapangan radiasi persegi. Berdasarkan hasil tersebut dapat disimpulkan bahwa verifikasi dosis radiasi penyinaran Linac milik RSP Universitas Andalas memiliki hasil yang baik dan dapat digunakan untuk mengobati pasien penyakit kanker.

\section{DAFTAR PUSTAKA}

BAPETEN Homepage,"Perka BAPETEN No.3 Tahun 2013 tentang Keselamatan Radiasi dalam Penggunaan Radioterapi", http://jdih.bapeten.go.id >files, diakses Februari 2018, (2013) 
IAEA Homepage,"IAEA HUMAN HEALT SERIES No. 31 Accuracy Requirements and Uncertainties in Radiotheraphy", http://www.iaea.org/-publications/index.html, diakses Februari 2018, (2016).

Grzadiel, A.,"Configuration And Pre-Treatment IMRT Verification", Oncology Radiother Journal, 12, 6, 307-312, (2007).

Peca, S., "A simple Method for 2-D In Vivo Dosimetry By Portal Imaging”, Technology In Cancer Reseach \& Treatment, 16, 6, 944-955, (2016).

Mayles, P.,"Handbook of Radiotherapy Physics : Teori and Practice", Taylor and Francis Group, New York, (2007).

Susworo, R.,"Dasar Dasar Radioterapi”, UI Press, Jakarta, (2007). 